\title{
Questes
}

vestes Revue pluridisciplinaire d'études médiévales

12 | 2007

La faim et l'appétit

\section{La faim et l'appétit : conclusion}

\section{Anne-Laure Lallouette}

\section{(2) OpenEdition}

Journals

Édition électronique

URL : http://journals.openedition.org/questes/2758

DOI : 10.4000/questes. 2758

ISSN : 2109-9472

\section{Éditeur}

Les Amis de Questes

\section{Édition imprimée}

Date de publication : 15 juin 2007

Pagination : 109-111

ISSN : 2102-7188

\section{Référence électronique}

Anne-Laure Lallouette, «La faim et l'appétit: conclusion», Questes [En ligne], 12 | 2007, mis en ligne le 15 janvier 2014, consulté le 15 septembre 2020. URL : http://journals.openedition.org/questes/2758 


\section{Conclusion}

\section{Anne-Laure LALLOUETTE}

$\mathrm{Au}$ terme de ce parcours il convient de revenir sur les multiples apports des différentes contributions de ce cycle de séances du séminaire de Questes consacrées à la faim et l'appétit.

La très grande richesse des interventions et des questions qu'elles ont suscitées atteste bien de la pertinence d'une analyse de ce moment qui se situe juste avant l'intervention des satisfactions corporelles, lorsque l'individu cherche à tout prix à assouvir des désirs qui peuvent être douloureux - à l'instar d'une faim entêtante - aussi bien qu'agréables - il suffit de penser ici au plaisir que semble prendre Merlin à contempler les mets qui sont préparés avec soin pour lui (Irène Fabry). Cette étape préliminaire connaît des durées variables : elle peut torturer pendant des journées entières de pauvres erres affamés, tels que ceux que décrit Eustache Deschamps (Clotilde Dauphant) ; quelques heures, le temps qu'une des maîtresses dépeintes dans les fabliaux préparent un bain brûlant et un repas plantureux pour son amant qui s'en délecte d'avance (Caroline Foscallo); voire quelques instants, quand les médecins invitent leurs patients à se nourrir précipitamment dès les premières sensations de faim (AnneLaure Lallouette).

Les différentes interventions ont permis de mettre au jour le foisonnement d'un imaginaire médiéval de l'alimentation, dans lequel abondance et manque se répondent et conditionnent la virulence de la faim ou de l'appétit. Certains textes littéraires insistent longuement sur la profusion d'aliments censée susciter un désir ardent. Les troupes nombreuses et superbement équipées de Charnage dans les débats étudiés par Laetitia Tabard, ou la nef chargée de « viandes » présentée 
au roi Mordrain dans La Queste del Saint-Graal analysée par Sophie Albert, sont de magnifiques exemples de luxuriance alimentaire, réponses possibles à l'angoisse médiévale de subir le manque endémique de nourriture et de ne pas échapper aux disettes récurrentes. Face à cette débauche culinaire, les auteurs rappellent qu'il convient de faire preuve de modération et de ne pas céder de manière désordonnée à ses appétits : Carême et ses troupes de désolation mènent un combat acharné contre Carnage (Laetitia Tabard), et les régimes de santé rappellent inlassablement les règles qui déterminent la consommation d'aliments et écartent en partie la notion d'appétit (Anne-Laure Lallouette).

Le lien très fort qui existe entre alimentation et sexualité, qui apparaît de manière si réjouissante dans les fabliaux (Caroline Foscallo), justifie à lui seul un encadrement strict de la première. La bonne chère excitant la chair, l'appétit alimentaire est représenté comme un préambule au désir sexuel. Le roi Mordrain est d'ailleurs châtié, au cours du roman, en raison de sa faim exagérée et de ses comportements sexuels déviants (Sophie Albert).

Inversement, la nourriture, essentielle au bon fonctionnement du corps, est un biais par lequel la chair peut être mortifiée. Le jeûne est considéré comme une forme de pénitence remarquable qui permet de dominer entièrement ses sens. Certaines saintes anorexiques poussent d'ailleurs ces pratiques à l'extrême, car elles sont l'occasion de reprendre possession de leur propre corps, souvent trop étroitement surveillé par leur famille et la société patriarcale à laquelle elles appartiennent. Ces attitudes mystiques trouvent une expression courtoise dans les récits de « cour mangé » (Mathilde Grodet). En effet, les épouses infidèles démasquées par leur mari, à qui l'on fait manger le cœur ou les parties génitales de leur amant, choisissent souvent de ne plus se nourrir, parfois jusqu'à la mort, faisant de leur faim un outil d'émancipation face à un époux devenu tortionnaire.

Les différentes intervenantes ont également montré que certains aliments, comme les poissons (Cécile Le Cornec), suscitent un grand intérêt. Aliments 
essentiels lors des périodes maigres, ces derniers peuvent être loués pour leurs qualités nutritives et gustatives (Cécile Le Cornec, Laetitia Tabard). Cependant, l'approvisionnement en produits de la mer reste encore délicat, et le manque de fraîcheur des étals de mareyeurs provoque aussi la moquerie de quelques auteurs comme Eustache Deschamps (Clotilde Dauphant). Les poissons avariés provoquent bien plus de répulsion que d'appétit, aussi grande que soit la faim de ceux à qui ils sont présentés. Les auteurs insistent sur l'idée qu'une faim dévorante ne justifie pas la consommation d'aliments considérés comme vils. Aldebrandin de Sienne vilipende ce qu'il appelle l'«appétit de chien » qui pousse les individus à manger des aliments de mauvaise qualité (Anne-Laure Lallouette) et le roi Mordrain est empêché de dévorer goulûment un méchant morceau de pain noir par une apparition extraordinaire (Sophie Albert). Ne doivent pas être consommés des aliments pour lesquels la plupart des personnes n'auraient aucun appétit.

La faim et l'appétit sont donc deux sensations clairement distinctes dans l'esprit des hommes du Moyen Âge, même si, du point de vue linguistique, le second ne se trouve que dans les textes les plus savants. Ces deux états du corps donnent lieu à des descriptions si passionnantes que le médiéviste ne peut que s'en délecter et attendre avec gourmandise d'en découvrir de nouvelles occurrences. 